\title{
Use of Microsatellite Markers for Assessing Genetic Variability in Wheat Genotypes for Yellow Rust Resistance
}

\author{
Meenakshi Rathi*, Mukesh Kumar, Vijay Kumar, Pooja and Lakshmi Chaudhary \\ Department of Genetics and Plant Breeding, College of Agriculture \\ Chaudhary Charan Singh Haryana Agricultural University, Hisar 125001, India \\ *Corresponding author
}

\section{A B S T R A C T}

Keywords

Microsatellite,

Yellow rust,

Diversity, PIC and

UPGMA cluster

Article Info

Accepted:

15 November 2018

Available Online:

10 December 2018
A set of sixty microsatellite markers were used to characterize 49 genotypes of wheat. Out of these, 23 markers showed polymorphism with a total of 170 alleles. Average number of SSR alleles per locus was 2.88 and ranges from 2 (Cfa2040, Xgwm261, Xgwm382, Xgwm413, Xgwm170, Wmx44, Cslv34, Xgwm501, Xgwm70, Barc136, Barc101, Xgwm352, Xgwm130, Barc187, Barc76, Wmc407) to 5 (Xgwm190). The PIC value varied from 0.11-0.65 and 7 out of 23 SSR loci, Xgwm261, Xgwm295, Xgwm190, Xgwm46, Gwm11, Xgwm273 and Xsps3000 had PIC value more than 0.5 thus considered very useful in estimating genetic diversity of the genotypes. The UPGMA cluster grouped into two, major cluster 1 consists of 6 sub clusters whereas major cluster 2 was not further fragmented and had only one genotype WH1191. Cluster pattern revealed that, sub-cluster 2 was the largest consisting maximum number of 24 genotypes. This cluster analysis grouped genotypes on the basis of similarity at DNA level, thus for selecting parents for hybridization program against yellow rust disease can be chosen from different clusters.

\section{Introduction}

Wheat (Triticum aestivum) is a hexaploid $(2 n=6 x=42)$ with genome composition of AABBDD and belongs to family Poaceae. It is one of the leading sources of carbohydrates, which has about one half of the human's food calories thus fulfills the large part of nutritional requirements. With progressive global climatic change wheat production is influenced greatly (Singh and Chaudhary, 2006). Whereas on other hand world population is increasing continuously, thus developing high yielding genotypes is the major concerned of today's scenario. The major states involved in wheat production are Uttar Pradesh, Punjab and Haryana which accounts nearly 70 per cent of the total wheat produced in the country. India occupies 34.64 mha area under wheat cultivation with production and productivity of $98.76 \mathrm{mt}$ and $30.60 \mathrm{q} / \mathrm{ha}$ respectively (Anonymous, 2016).

Genetic diversity in crop species is essential and basic for breeding program to develop varieties resistant to yellow rust disease. Reduction in the genetic variability makes the crops increasingly vulnerable to diseases and 
adverse climatic changes (Aremu, 2012). Morphological traits are influenced by the environmental factors thus cannot be used to characterize genetic diversity (Spanic et al., 2012).

These days DNA markers have been used extensively for estimation of genetic diversity in wheat. Among all the DNA markers, simple sequence repeats (SSR's) are frequently used markers for dissecting genetic diversity. These markers are highly reliable as they show high polymorphism, co-dominant inheritance and good reproducibility (Plaschke et al., 1995; Roeder et al., 1995; Ma et al., 1996; Bryan et al., 1997). Wheat has an extremely large genome size of $17 \times 109$ base pairs with more than $80 \%$ repetitive DNA (Bennett and Smith, 1976) thus SSR markers are best for use in this crop. In present research genotypes were evaluated for genetic diversity using SSR markers and their relatedness is measured. This information helps to select batter parents for further breeding programs and developing high yielding yellow rust resistant varieties.

\section{Materials and Methods}

\section{Plant material}

A total of 49 genotypes (Table 1) including released varieties and advanced lines were grown in paired rows and infector row on borders were evaluated. Artificial inoculation was carried out in field condition with pst (Puccinia striiformis) of races 46S102, 47S103 and 78S84 by spraying urediospores suspension.

The disease data were recorded following modified Cobb's scale (Peterson et al., 1948). The screening, for reaction to stripe rust, was done and on the basis of that genotypes were classified as highly resistant (HR), moderately resistant (MR), moderately susceptible (MS) and highly susceptible (HS).

\section{DNA isolation}

Genomic DNA was isolated from the young leaves of wheat plants using CTAB (Cetyl Trimethyl Ammonium Bromide) extraction method given by Murray and Thompson (1980) and modified by Saghai- Maroof et al., (1984). DNA samples were treated with $1 \mu \mathrm{l}$ of RNase A solution (10mg/ml) per $50 \mathrm{ng}$ DNA sample to remove RNA contamination. Qualitative and Quantitative estimation of genomic DNA was estimated by UV spectrophotometer readings at $260 \mathrm{~nm}$ as well as $280 \mathrm{~nm}$ wavelengths. Quantity of DNA is calculated by following formulae:

DNA $(n g / \mu l)=$ A260 $\times$ Dilution factor $\times 50$

The ratio of absorbance at $260 \mathrm{~nm}$ and $280 \mathrm{~nm}$ was calculated. Samples with a ratio of 1.7 to 1.8 were considered to be of good quality and band intensity was measured by running DNA on $0.8 \%$ agarose gel.

\section{Molecular markers}

A total of sixty molecular markers were used for studying molecular polymorphism in 49 genotypes of wheat consisting of released and advance lines.

\section{Polymerase Chain Reaction (PCR) amplification}

Applied biosystem thermocycler was used for PCR amplification. The Optimization of PCR reaction was done by varying the concentrations of master mix ingredients. The optimized reaction contained 50ng DNA template in $10.00 \mu \mathrm{l}$ of master mix with 0.30 $\mu \mathrm{MgCl} 250 \mathrm{mM}, 0.25 \mu \mathrm{ldNTPs} \operatorname{mix}(10 \mu \mathrm{M})$, $0.20 \mu \mathrm{l}$ of Forward primer and Reverse primer each, $7.00 \mu$ Sterile distilled water and 3 units of Taq polymerase. The PCR conditions were set at $94^{\circ} \mathrm{C}, 4$ minutes for initial denaturation then again at $94^{\circ} \mathrm{C}, 1$ minute for further denaturation. Primer annealing temperature 
ranged from $48.5-70^{\circ} \mathrm{C}$ which existed for 1 minute and extension was attained at $72{ }^{\circ} \mathrm{C}$ for 2 minutes then again $72^{\circ} \mathrm{C}, 10$ minutes for final primer extension. The cycle was repeated from step (ii) to (iv) for 35 times and the amplified products were stored at $-20^{\circ} \mathrm{C}$ till further use.

\section{Agarose gel electrophoresis}

PCR amplified DNA fragments were resolved on $2.5 \%(\mathrm{w} / \mathrm{v})$ agarose gels. Agarose was melted in $0.5 \mathrm{X}$ TBE buffer and ethidium bromide $(1 \mu \mathrm{l} / 50 \mathrm{ml})$ was added. Gel was submerged using $0.5 \mathrm{X}$ TBE buffer. Electrophoresis was carried out at constant voltage $(3 \mathrm{v} / \mathrm{cm}$ of gel) for 2.5 hours. PCR amplified products were viewed under UV light using photo UV trans-illuminator and image was captured using gel documentation system.

\section{Allele scoring}

The size of amplified band of each primer was determined based on electrophoretic mobility relative to molecular weight of ladder (100 bp) used. The presence of band run on agarose gel was taken as one and absence of band was read as zero. The binary data was used to calculate similarity genetic distance using 'simqual' sub-program of software NTSYSPC (Rohlf, 1992) and dendrogram was constructed on similarity bases.

\section{Results and Discussion}

Earlier genetic diversity analysis was limited to morphological variation seen in the genotypes under studies. However, there are some problems with the $\mathrm{u}$ e of morphological traits, first being limited in number and second; it is greatly influenced by the environment and by genotype $\times$ environment interactions. DNA based markers provide an alternative as they are unlimited in number and are not influenced by the environment. In present studies 60 microsatellite markers were used for diversity analysis of 49 wheat genotypes. Out of 60 primers 57 primers were amplified and 23 gave polymorphic results. The remaining 34 gave monomorphic band. Twenty three polymorphic SSR markers were dispersed over the wheat genome (AABBDD), with allele range 1-5 and a total of 170 alleles were detected (Table 2).

The average number of SSR alleles per locus was 2.88, with a range from 2 (Cfa2040, Xgwm261, Xgwm382, Xgwm413, Xgwm170, Wmx44, Cslv34, Xgwm501, Xgwm70, Barc136, Barc101, Xgwm352, Xgwm130, Barc187, Barc76, Wmc407) to 5 (Xgwm190). Number of alleles detected per SSR locus as well as polymorphism information content (PIC) values for each of the SSR loci are summarized in Table 3 (Plates 1, 2 and 3). Prasad et al., in 2000 used a set of 20 markers with 55 wheat genotypes for diversity analysis. Twenty-one loci detected a total of 155 alleles with average of 7.4 alleles per locus. In the studies by Pal et al., 2015 alleles per marker varied from 2 to 5 with an average of 2.67 per locus.

Polymorphic information content is a measure of informativeness or usefulness of a DNA marker for linkage studies. The PIC value reflects allele diversity and frequency among the wheat cultivars.PIC values of various SSR loci across all the 49 genotypes ranged from 0.11(Xgwm130) to 0.65 (GWM11). Seven out of twenty three SSR loci, Xgwm261, Xgwm295, Xgwm190, Xgwm46, Gwm11, Xgwm273 and Xsps3000 had PIC value more than 0.5 which can be considered highly useful for differentiation of wheat genotypes, studying their genetic diversity and phylogenic relationships. Medini et al., (2005) found highest PIC value as 0.68 by SSR markers in the analysis of genetic variability. Whereas Prasad et al., (2000) found it 0.71. 
Table.1 List of 49 wheat genotypes used in the present study

\begin{tabular}{|c|c|c|c|c|c|}
\hline Sr. No. & GENOTYPES & Sr. No. & GENOTYPES & Sr. No. & GENOTYPES \\
\hline $1 \mathrm{~s}$ & C -306 & 18 & WH 1166 & 35 & WH 1193 \\
\hline 2 & WH-542 & 19 & WH 1164 & 36 & WH 1194 \\
\hline 3 & WH 711 & 20 & WH 1157 & 37 & WH 1197 \\
\hline 4 & WH 730 & 21 & WH 1156 & 38 & RAJ 3765 \\
\hline 5 & WH 1021 & 22 & WH 1154 & 39 & PBW 698 \\
\hline 6 & WH 1025 & 23 & WH 1142 & 40 & PBW 550 \\
\hline 7 & WH 1080 & 24 & WH 1182 & 41 & PBW 373 \\
\hline 8 & WH 1097 & 25 & WH 1183 & 42 & PBW 343 \\
\hline 9 & WH 1105 & 26 & WH 1184 & 43 & PBW 175 \\
\hline 10 & WH 1124 & 27 & WH 1185 & 44 & HD 3086 \\
\hline 11 & WH 1181 & 28 & WH 1186 & 45 & HD 2967 \\
\hline 12 & WH 1180 & 29 & WH 1187 & 46 & DPW 621-50 \\
\hline 13 & WH 1173 & 30 & WH 1188 & 47 & DBW 88 \\
\hline 14 & WH 1172 & 31 & WH 1189 & 48 & DBW 17 \\
\hline 15 & WH 712 & 32 & WH 1190 & 49 & WH 1195 \\
\hline 16 & WH 1169 & 33 & WH 1191 & & \\
\hline 17 & WH 1167 & 34 & WH 1192 & & \\
\hline
\end{tabular}

Plate.1 Allelic pattern in 49 genotypes of wheat using marker Cfa2040

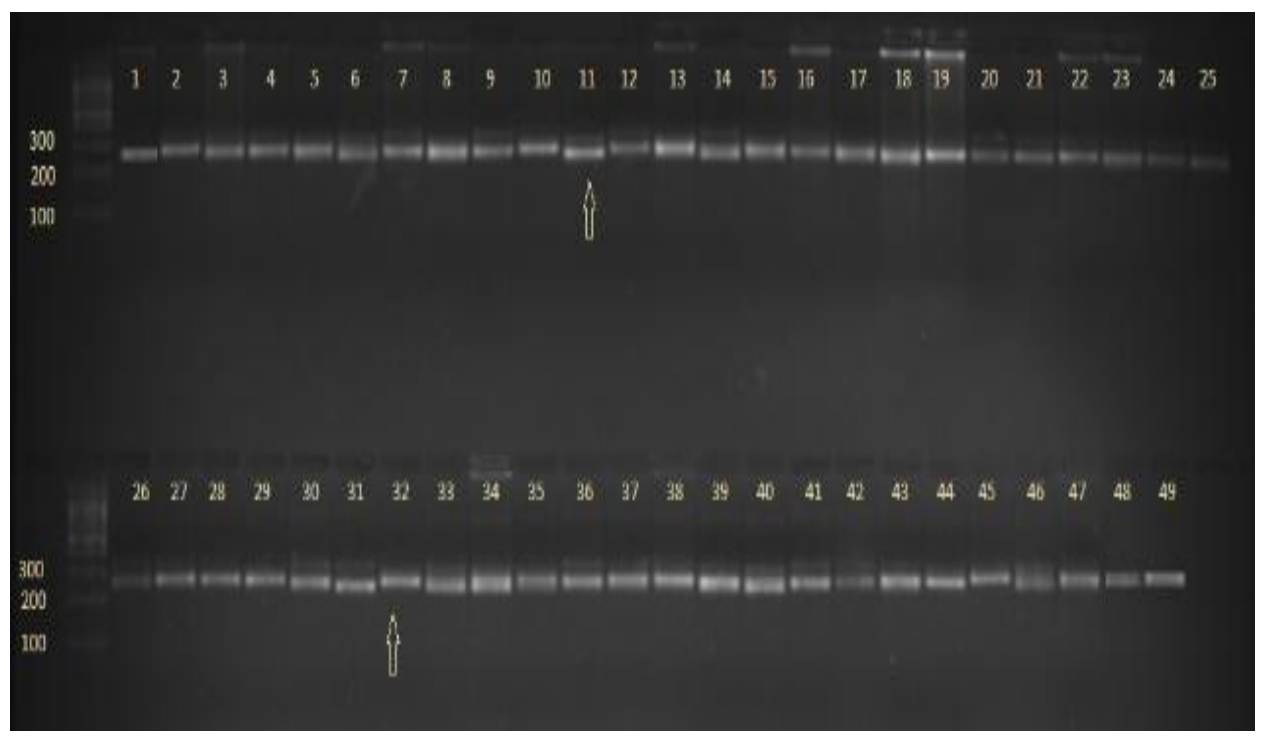


Table.2 Allelic diversity among forty nine genotypes as assessed by SSR markers

\begin{tabular}{|l|c|}
\hline Number of markers used & $\mathbf{6 0}$ \\
\hline Polymorphic primers & 23 \\
\hline Monomorphic primers & 34 \\
\hline Range of alleles & $1-5$ \\
\hline Total number of alleles & 170 \\
\hline Average number of alleles & 2.88 \\
\hline
\end{tabular}

Table.3 Band size, allele number and PIC value of polymorphic markers

\begin{tabular}{|c|c|c|c|c|}
\hline MARKER & & Number of & Bp & PIC \\
\hline Xcfa2040 & & 2 & $255-270$ & 0.30 \\
\hline Xgwm261 & & 2 & $180-200$ & 0.50 \\
\hline Xgwm295 & Yr18 & 3 & $230-620$ & 0.57 \\
\hline Xgwm382 & Yr1 & 2 & $130-600$ & 0.17 \\
\hline Xgwm413 & Yr15 & 2 & $100-120$ & 0.30 \\
\hline Xgwm170 & & 2 & $230-250$ & 0.32 \\
\hline Wmc44 & Yr29 & 2 & $200-250$ & 0.22 \\
\hline Barc181 & Yr26 & 2 & $180-210$ & 0.49 \\
\hline Xgwm190 & & 5 & $150-600$ & 0.56 \\
\hline Cslv 34 & Yr18 & 2 & $170-220$ & 0.25 \\
\hline Xgwm501 & Yr5 & 2 & $150-170$ & 0.18 \\
\hline Xgwm46 & & 3 & $140-450$ & 0.56 \\
\hline Gwm11 & Yr15 Yr24 & 3 & $200-550$ & 0.65 \\
\hline Xgwm70 & & 2 & $170-190$ & 0.15 \\
\hline Barc136 & & 2 & $280-300$ & 0.40 \\
\hline Barc 101 & Yr36 & 2 & $115-130$ & 0.27 \\
\hline Barc352 & & 2 & $250-270$ & 0.21 \\
\hline Xgwm130 & Yr7 & 2 & $110-130$ & 0.11 \\
\hline Barc187 & Yr24 & 2 & $110-190$ & 0.15 \\
\hline Xgwm273 & YrH52 & 3 & $150-200$ & 0.63 \\
\hline Barc76 & & 2 & $200-220$ & 0.18 \\
\hline Xwmc407 & & 2 & $120-150$ & 0.18 \\
\hline Xsps3000 & Yr10 & 3 & $200-270$ & 0.51 \\
\hline
\end{tabular}

Table.4 Distribution of forty nine wheat genotypes in different clusters based on SSR markers

\begin{tabular}{|c|l|l|c|}
\hline Major cluster & Sub cluster & \multicolumn{1}{|c|}{ Genotypes } & Number \\
\hline \multirow{3}{*}{ Cluster1 } & Subcluster 1 & C306, WH1021, WH1025, WH542, WH711, WH730, WH1190, & 10 \\
\cline { 2 - 4 } & Subcluster 2 & WH1175, WH1157, WH1195, WH1172, WH1166, WH1164, & 24 \\
\cline { 2 - 4 } & Subcluster 3 & WH1080, WH1105, WH1097, WH1188, WH1181, WH1167, & 8 \\
\cline { 2 - 4 } & Subcluster 4 & WH1186, WH1187 & 2 \\
\cline { 2 - 4 } & Subcluster 5 & PBW343 & 1 \\
\cline { 2 - 4 } & Subcluster 6 & PBW698, WH1124, PBW550 & 3 \\
\hline
\end{tabular}


Plate.2 Allelic pattern in 49 genotypes of wheat using marker Barc136

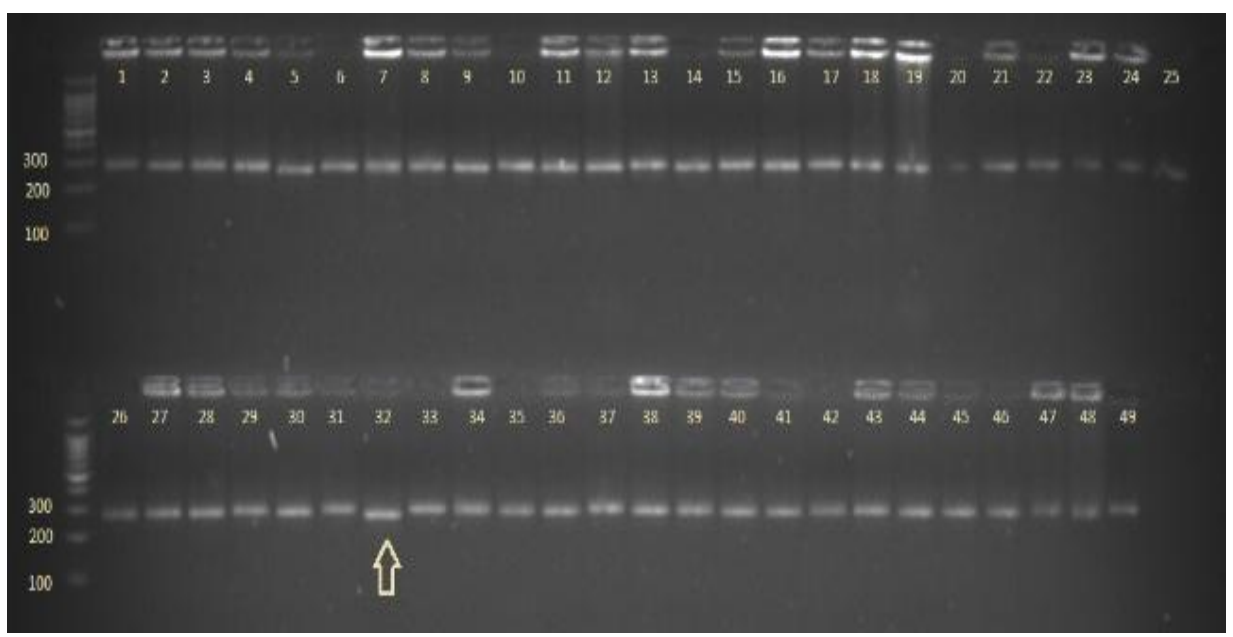

Figure.1 Dendrogram showing the clustering pattern of forty nine genotypes of wheat on the basis of SSR marker

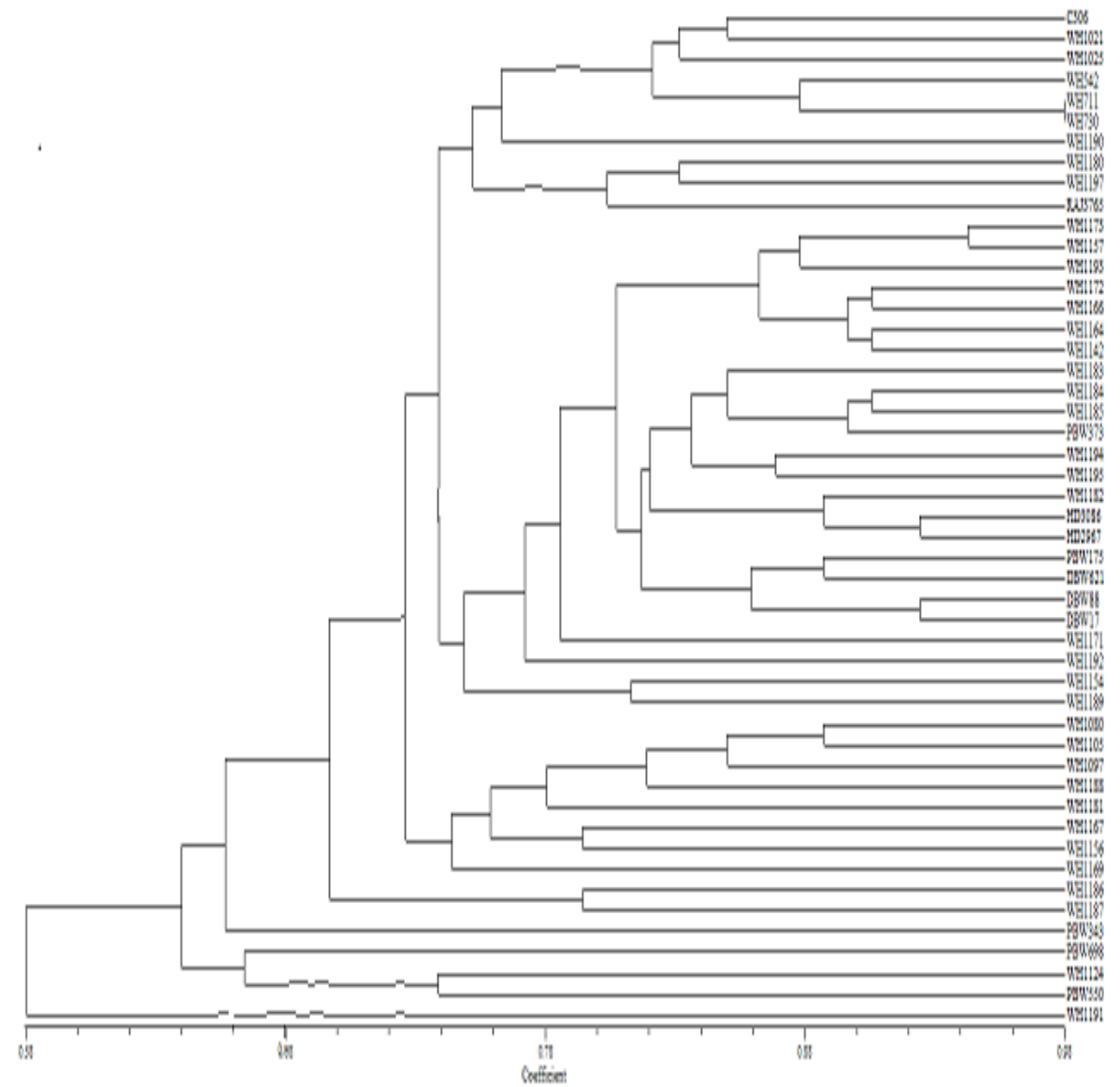




\section{Cluster analysis}

The data obtained using SSR microsatellite was further used to construct similarity matrices among 49 released and advance lines using "SIMQUAL" sub- programme of software NTSYS-pc. The allelic diversity was used to produce a dendrogram using 'cluster tree analysis' which revealed the genetic linkage and proximity among all the genotypes. The unweighted pair group method using arithmetic averages (UPGMA) cluster tree analysis led to the grouping of forty nine wheat genotypes in 2 major clusters and major cluster 1 is fragmented into $6 \mathrm{sub}$ clusters (Table 4) (Fig. 1). Cluster pattern revealed that, sub-cluster 2 was the largest consisting maximum number of 24 genotypes. This way followed by sub-cluster 1 (10genotypes), sub-cluster 3 (8 genotypes), sub-cluster 6 (3 genotypes), sub-cluster 4 (2 genotypes) and sub-cluster 5 had only 1 genotype. The major cluster 2 also had only one genotype WH1191.UPGMA algorithm, distributed the genotypes into two major clusters (I and II), each with two sub-clusters (Prasad et al., 2000). Zhang et al., (2005); Sehgal et al., (2012); and Pal et al., (2015) also did cluster analysis in their studies.

In conclusion, genetic variability in elite germplasm is a pre-requisite for any breeding programme aimed towards the improvement of traits like resistance and productivity. Selection of diverse parents in hybridization also needs molecular marker assistance. Keeping in view, efforts have been made to predict the prospects of developing superior genotypes through genotyping. Present study analyzes 49 genotypes using 60 microsatellite markers out of which 23 were polymorphic.PIC value obtained more than 0.5 shows high usefulness for differentiation of wheat genotypes. Different cluster formation depicts the diversity of the genotypes and selection of parents for hybridization can be done from different clusters. From the present studies it could be concluded that evaluation of germplasm is an important step in plant breeding programme so that the potential genotypes can be identified and used for further improvements. Molecular markers are essential tools for fastening the process of variety development programme. It is further suggested that more polymorphic wheat microsatellites could be used for efficient screening of the germplasm by saturating more regions of the wheat genome.

\section{References}

Anonymous (2016). Progress report of all India coordinated wheat and barley improvement project 2015-16. 01, Crop improvement. Directorate of Wheat Research, Karnal, India.

Aremu O (2012). Exploring Statistical Tools in Measuring Genetic Diversity for Crop Improvement, Genetic Diversity in Plants, Prof. Mahmut Caliskan (Ed.), ISBN: 978-953-51-0185-7.

Bennett MD and Smith JB (1976). Nuclear DNA amounts in angiosperms. Philosophical Transactions of the Royal Society of London Biological Sciences 334(1271), 309-345.

Bryan GJ, Collins AJ, Stephenson P, Orry A, Smith JB and Gale MD (1997). Isolation and characterization of microsatellites from hexaploid bread wheat. Theor Appl Genet 94: 557-563.

Ma ZQ, Roeder MS and Sorrells ME (1996). Frequencies and sequence characteristics of di-, tri- and tetranucleotide microsatellites in wheat. Genome 39: 123-30

Medini M, Hamza S, Rebai A, and Baum M (2005). Analysis of genetic diversity in Tunisian durum wheat cultivars and related wild species by SSR and AFLP markers. Genet Resour Crop Evol 
52(1): 21-31.

Murray MG and Thompson WF (1980). Rapid isolation of high molecular weight plant DNA. Nucleic Acids Res 8: 4321-4325.

Pal D, Bhardwaj S C, Sharma D, Kumari S, Patial M, and SharmaP (2015). Assessment of genetic diversity and validating rust resistance gene sources using molecular markers in wheat (Triticum aestivum L.). SABRAO J Breed Genet 47(2).

Plaschke J, Ganal MW and Roeder MS (1995). Detection of genetic diversity in closely related bread wheat using microsatellite markers. TheorAppl Genet 91:1001-1007.

Prasad M, Varshney RK, Roy J K, Balyan H S and Gupta P K (2000). The use of microsatellites for detecting DNA polymorphism, genotype identification and genetic diversity in wheat. TheorAppl Genet 100(3-4): 584-592.

Roeder MS, Plaschke J, Koenig SU, Boerner A, Sorrells ME and Tanksley SD (1995). Abundance, variability and chromosomal location of microsatellites in wheat. Mol Gen Genet 246: 327- 33

Rohlf FJ (1992). NTSYS-pc: numerical taxonomy and multivariate analysis system. Appl. Biostat.

Saghai-Maroof, MA, Soliman KM, Jorgensen RA and Allard RW (1984). Ribosomal DNA spacer-length polymorphism in Barley: Mendelian inheritance, Chromosomal-location and population dynamics. Proceedings of National Academy and Sciences, U.S.A. 81: 8014-8019.

Sehgal S A, Tahir R A and Nawaz M (2012).Molecular characterization of wheat genotypes using SSR markers. Int J Bioautomation, 16(2):119-128.

Singh G and H Chaudhary (2006). Selection parameters and yield enhancement of wheat (Triticum aestivum L.) under different moisture stress condition. Asian J Plant Sci 5: 894-898.

Spanic V, Buerstmayr $H$ and Drezner G (2012).Assessment of genetic diversity of wheat genotypes using microsatellite markers. Periodicum Biologorum 114: 37-42.

Zhang P, Reif JC, Dreisigacker S, Warbourton ML, Ginkel M, Hoisington D, Bohn M and Melchinger AE (2005). Wheat genetic diversity during domestication and breeding. Theor Appl Genet 110 (5):859-64.

\section{How to cite this article:}

Meenakshi Rathi, Mukesh Kumar, Vijay Kumar, Pooja and Lakshmi Chaudhary. 2018. Use of Microsatellite Markers for Assessing Genetic Variability in Wheat Genotypes for Yellow Rust Resistance. Int.J.Curr.Microbiol.App.Sci. 7(12): 1907-1914. doi: https://doi.org/10.20546/ijcmas.2018.712.221 